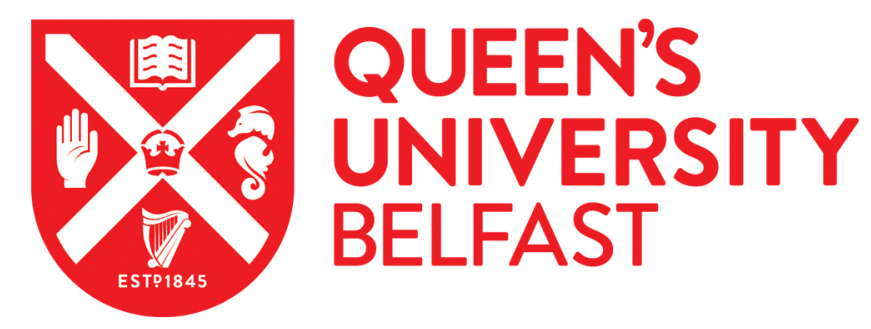

\title{
Investigating the P300 Response as a Marker of Working Memory in Virtual Training Environments
}

Simpson, T. G., \& Rafferty, K. (2021). Investigating the P300 Response as a Marker of Working Memory in Virtual Training Environments. IEEE Transactions on Human Machine Systems.

https://doi.org/10.1109/THMS.2021.3064815

Published in:

IEEE Transactions on Human Machine Systems

Document Version:

Peer reviewed version

Queen's University Belfast - Research Portal:

Link to publication record in Queen's University Belfast Research Portal

Publisher rights

Copyright 2021 IEEE.

This work is made available online in accordance with the publisher's policies. Please refer to any applicable terms of use of the publisher

\section{General rights}

Copyright for the publications made accessible via the Queen's University Belfast Research Portal is retained by the author(s) and / or other copyright owners and it is a condition of accessing these publications that users recognise and abide by the legal requirements associated with these rights.

Take down policy

The Research Portal is Queen's institutional repository that provides access to Queen's research output. Every effort has been made to ensure that content in the Research Portal does not infringe any person's rights, or applicable UK laws. If you discover content in the Research Portal that you believe breaches copyright or violates any law, please contact openaccess@qub.ac.uk. 


\title{
Investigating the P300 Response as a Marker of Working Memory in Virtual Training Environments
}

\author{
Thomas G. Simpson and Karen Rafferty, Senior Member, IEEE
}

\begin{abstract}
Conventional performance metrics fail to offer highresolution evaluation of learning and memory during training tasks; the P300 component of the event-related potential (ERP) is a promising tool for enhancing the assessment of training quality in virtual environments, but this technique is yet to be investigated. A driver training simulator and scenario were developed to explore the capability of the P300 for this purpose. A user study was conducted with 32 participants divided into 2 groups objectively determined by driving performance scores, thus enabling observations of the $\mathbf{P 3 0 0}$ response to be equated to varying levels of learning and memory. Participant electroencephalogram (EEG) data was recorded during the procedure, which was post-processed to filter and extract ERPs to capture neural responses to specific events in the virtual training scenario. These were combined to produce a result for each participant, which was then grand averaged to create an overall ERP for each group. Across the eight electrode sites statistically significant differences were found between the grand average waveforms of the two groups, with high memory retention producing significantly greater peak to peak amplitude $(U=9.00, p=.045)$, peak latency $(U=0.00, p<.001)$, and positive area $(U=13.00, p$ $=.05)$ of the waveform than low memory retention. The evidenced relationship between the $\mathbf{P 3 0 0}$ response and working memory in this context suggests it has the potential for monitoring learning and memory in stimulus-driven virtual training systems.
\end{abstract}

Index Terms-EEG, P300, virtual training environments, driving simulator.

\section{INTRODUCTION}

$\mathbf{S}$ KILL acquisition is essential for human development; from recreational activities to pursuing high-levels of competency in a professional capacity, the demand for accessible and optimised training systems is eminent [1]. Virtual training systems demonstrate the potential to improve learning practices under certain conditions by introducing features such as haptics [2]-[4], enhanced visual information [5]-[8], and intelligent tutoring [9]-[11], that combine for a unique and dynamic pedagogical tool. With the advent of VR and $\mathrm{AR}$, virtual systems could offer ubiquitous, effective, and affordable training solutions, with diverse libraries of skills in the near future.

Successful training requires a high-cohesion between the participant and system to enhance distribution of relevant skill information, yet there are limited objective techniques available to determine the quality of training provided by virtual systems. Common techniques to monitor training quality typically measure pre and post-training performance using metrics including error counting, completion time, performance questionnaires, and task dependent objective metrics [2], [5],

Manuscript received MONTH DAY, YEAR; revised MONTH DAY, YEAR.
[8], [12]-[15]. These descriptions are revealing but insufficient for reliable evaluation of perception and comprehension of individual training elements. They can be advanced by combining electrophysiological metrics to develop transparency with the learning process and cultivate further understanding of a candidate's training profile, and the relationship that has with post-training performance.

The EEG can be used as an additional monitor of training quality by inferring psychological states of the human involved. This electrophysiological monitoring method operates by recording brain activity which can be used to assess cognitive behaviour such as mental workload [16], [17], emotion [18], [19], and fatigue [20], in a passive brain-computer interface (pBCI) configuration [21], [22], with varying degrees of success. Another popular technique for monitoring neurological processing is the ERP, which is generated by the firing of cortical neurons in response to a stimulus [23]. One of the most studied components of this response is the P300, a voltage deflection at approximately $300 \mathrm{~ms}$, which is utilised in a range of applications, particularly in the medical sector [24]-[26] and for cognitive workload [27].

The objective of the presented experiment is to investigate the relationship between the P300 response and working memory in the context of a virtual training environment, an application currently unexplored in the literature. Participant improvement rankings from pre and post-performance assessment in a driver training simulator yield High Retention (HR) participants and Low Retention (LR) participants as two categorical independent groups. These are compared to observe the effect induced on the P300 component of the ERP, to demonstrate how participant neural activity modulates when learning instructional cues in an applied context. These groups are then further decomposed to ascertain greater resolution of improvement score to better observe the effect.

The remainder of this paper chronicles work related to this study, followed by descriptions of the system design and experiment procedure, along with presentation and analysis of the results.

\section{RELATED WORK}

\section{A. EEG in Human-Machine Systems}

There is a developing corpus of literature dedicated to EEG analysis techniques for human-machine systems, yet applications specifically for training contexts are currently limited, this review will hence focus on related available technology.

Data is typically acquired directly from the human component of the system via the EEG headset, which is analysed 
with various possible techniques contingent on the psychological information required. Spectral analysis is one of the standard methods used to quantify EEG data, where the Power Spectral Density (PSD) component reflects the distribution of signal power over frequency [28], which is employed for a variety of applications in medicine [29], [30]. In many of these measurement-based systems the subject does not actively, explicitly, or voluntarily modulate EEG activity, instead focussing on the task [31]; this popular configuration is known as pBCI. In both real and virtual human-machine systems, PSD has been integrated to estimate levels of driver drowsiness [32], [33], in a pBCI configuration, allowing for interventions that improve safety and well-being of system users. This is accomplished with focus on the theta (4-7hz) and alpha (8-12hz) bands [34], [35], which studies have correlated with fatigue [36]. This technique demonstrates high-detection accuracies [37] and is typically applied in conjunction with other physiological measurements to improve efficacy [38].

There is strong evidence in the literature that EEG rhythm oscillations are a basic form of communication between cortical assemblies [39]. This effect has been utilised to observe relationships between psychological responses and rhythm oscillations to produce further insight into neurological processes, such as evidence to suggest that episodic memory operations are related to theta band synchronisation, whereas semantic memory demands are associated with desynchronisation in the upper alpha band [40]. Furthermore, high workloads have been shown to increase beta activity, which has also been linked with changes in alertness and stress [41]. This technique has been implemented for examining cognitive workload in virtual training environments such as flight simulators. This method is supported by findings that delta and beta band activity increases with cognitive workload [42], [43] while gamma band activity decreases, providing an objective metric of mental effort in response to a task. This technique allows an automated system to adapt to the workload level of a human operator, beneficial in industrial workplaces and safety critical environments such as human-machine operation [44].

Multiple techniques for extracting psychological information from EEG data have been presented, with cognitive workload and fatigue the most pertinent for a prospective training system. These attributes are effective tools for understanding the training experienced by a participant, but their unreliable relationship with learning and memory make them inadequate measures of retention. These techniques are also inappropriate for capturing immediate responses to instruction, establishing a research aperture for a measurement technique that can successfully detect learning and memory in a stimulus-driven training context.

\section{B. The P300 Response}

The ERP is an index of brain activity obtained from observing variations in electrical signals produced by the firing of cortical neurons, which facilitates evaluation of rapid alterations in neural processing [23]. More specifically, these represent the summation of postsynaptic potentials from populations of synchronously active, primarily cortical neurons
[45], [46], that generate a signal strong enough to be detected at the scalp.

ERP exhibitions of neural activity are normally related to specific information processing associated with a stimulus [23]. The P300 component of the ERP is one of the most frequently reported ERP components in information processing [47] and is characterised by a positive voltage deflection occurring between $250-400 \mathrm{~ms}$ after delivery of a rare or task-relevant stimulus within a train of frequent or nonrelevant stimuli [48], [49]. This component is closely related to attentional resource allocation and working memory in both frontal and parietal regions in the brain [50].

One common technique to elicit the P300 is the oddball paradigm, which involves presentations of repetitive stimuli, termed the frequent, which are infrequently interrupted by a deviant stimulus, termed the oddball, which elicits a P300 response in the brain of the participant. This technique is adopted frequently and enables researchers to examine the response induced by different variables, facilitating much research related to neural processing in patients with medical conditions including schizophrenia [51], Alzheimers [52], and old age [53]. For example, the P300 has been demonstrated as providing useful information relevant for diagnosis of Alzheimers in the early stages, as patients typically exhibit reduced amplitudes and longer latencies [54] indicative of deteriorating neural functionality.

The P300 has also been used to measure workload [55], [56] by exploiting the inversely proportional relationship to P300 amplitude evoked with the oddball paradigm, as allocated mental faculties compromise processing of the stimuli.

Other research has predicted memory and learning capabilities of subjects by correlating ERPs elicited by the oddball paradigm with results from memory and learning tests [57], finding that larger P300 amplitude correlated with higher test scores, reinforcing the association between ERPs and learning performance.

Virtual training systems could one day be ubiquitous, and it will be important to observe the extent to which participants are learning for personalisation and optimisation purposes. The P300 signal is frequently used in medical science and neuroscience applications, but its potential for assisting in analysing learning and memory in a training context is promising. The relationship between the P300 and working memory suggests that the signal could be a valuable metric for detecting retention in virtual training systems, but there is little research in these applied environments evaluating the suitability for this purpose.

\section{SySTEM DESIGN}

A driver training scenario was designed in Unity Game Engine, software for developing interactive 3D virtual environments. The course was constructed using various components available on the Unity Asset Store such as models for a vehicle, track sections, trees, grass, and barriers. An aerial image of the developed course is depicted in $2 \mathrm{a}$. It was designed to be demanding to help capture improvement, yet concise to sustain participants concentration levels throughout 
the task. The vehicle physics were adjusted to be realistic but also punishing for incorrect inputs, so that following the instructions significantly benefited the participant.

The simulator was physically comprised of a Playseat Evolution racing chair, a Logitech G920 driving force racing wheel and floor pedals, and a NEC LCD 46 inch monitor with a resolution of 1920x1080 pixels, as seen in Fig 1.

Zones were created around the course where subjects would be expected to perform a particular action, dictated by a set of sequential, location based, visual instructions. This was facilitated by a set of coloured transparent walls situated at certain intervals around the track, where the colour was indicative of the required response. As the subject advanced into the instruction, they were expected to perform the corresponding reaction at the moment of contact. For example, if a subject travelled into one of the red transparent walls (visible in Fig $2 b$.) they were required to brake at the moment of contact, and to continue this action until contact with a different instruction. Green instructions indicated the required response was acceleration, with red for braking, and yellow for coasting ${ }^{1}$. The location of these instructional cues were determined in collaboration with the Queen's University Belfast Racing Team and are designed for efficient traversal of the course.

To explore the effect of modality, an Arduino based vibrotactile system was developed to generate vibrations to the relevant sensory input at the moment an instruction was encountered. For example, if the instruction was to accelerate, the vibration module attached to the right foot of the participant would vibrate to act as an additional prompt to respond. This utility was enabled for 16 of the 32 participants.

The capturing of the P300 component was accomplished using scripting in $\mathrm{C \#}$, triggered at the frame the instructional cue is encountered. At this moment a signal was transmitted from Unity to the Neuroelectrics Instrument Controller (NIC) software, that accompanies the Enobio-8 EEG headset, using Lab Streaming Layer (LSL) marker streams. The timing of contact with the instructional cue was recorded and synchronised with the EEG signal. It was at this moment that the brain processed the information given by the instruction, and an ERP was elicited. A file was recorded in the NIC software that contains the voltage amplitude of each given electrode and the corresponding timings, as well as a marker for each instructional cue encountered. This allowed analysis to be conducted in ERPLAB, an extension of EEGLAB [58] which is an interactive MATLAB toolbox for processing continuous and event-related EEG data, by the Swartz Center of Computational Neuroscience.

\section{A. EEG Headset}

The headset utilised was the Enobio-8, a dry electrode EEG headset by Neuroelectrics that operates wirelessly using Bluetooth. It was connected to the main system throughout all studies to facilitate recording of the EEG data throughout the experiment. Data was collected at a sampling rate of $500 \mathrm{~Hz}$ from the sites $\mathrm{F}_{3}, \mathrm{~F}_{4}, \mathrm{~F}_{7}, \mathrm{~F}_{8}, \mathrm{~F}_{\mathrm{z}}, \mathrm{C}_{\mathrm{z}}, \mathrm{P}_{\mathrm{z}}, \mathrm{O}_{\mathrm{z}}$, and referenced to the right mastoid.

\footnotetext{
${ }^{1}$ Neither accelerating nor braking
}

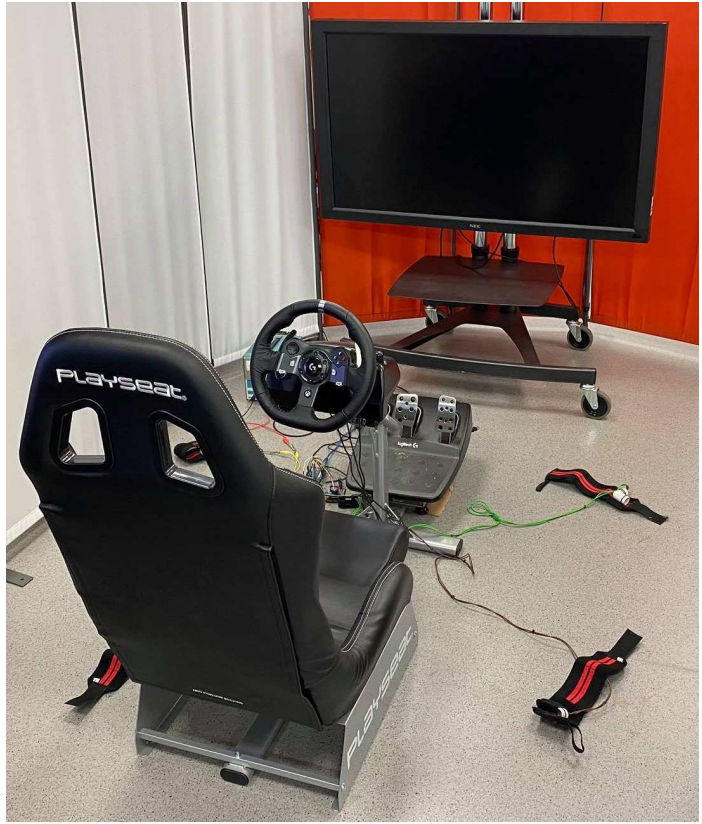

Fig. (1) Driving Simulator

\section{EXPERIMENT DESIGN}

\section{A. Objectives}

The primary objective of this study was to examine the relationship between the P300 and working memory in virtual training environments, which was accomplished by observing differences in the elicited P300 response for variations in retention.

\section{B. Design}

A controlled between-subjects experiment with a $2 \times 2$ factorial design was executed with 8 subjects in each of 4 different groups. The first independent variable was the information type of the instruction, which could be either visual-haptic or visual. Two further groups were created based on objective simulation metrics yielding the second independent variable of retention, consisting of the sub-groups HR and LR (see Section IV. E). There are hence four groups: HR visualhaptic, LR visual-haptic, HR visual, and LR visual. This paper focuses on the main effect observed on the P300 response when the retention variable is modulated. Results regarding modality are not explored in this paper, as no statistically significant differences were found between visual and visualhaptic groups for performance improvement (see Section VI.), suggesting that modality has not influenced learning and memory, which is the subject of this paper. The experiment is designed to eliminate any interference of the additional haptic modality by including equal proportions of visual and haptic participants in each retention group.

All groups were given the same input location and timing information but in slightly different modalities. All received the same visual instructions, but the visual-haptic group had additional vibrating motors attached to the ankles, which activated at the moment of contact with the instructional cue as stimulation to execute the command. 


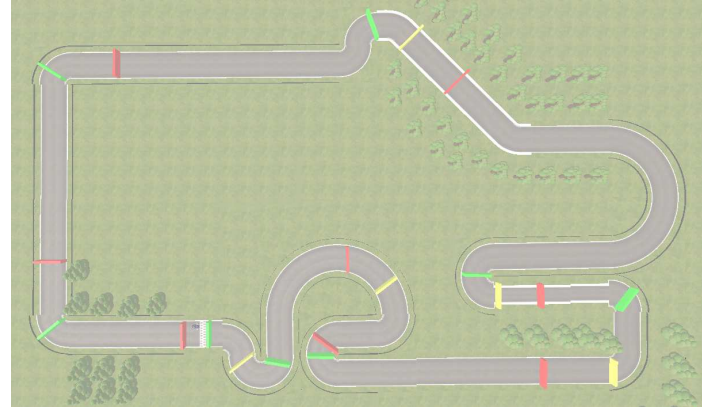

(a) Aerial view of course including instructions, rendered as opaque for clarity

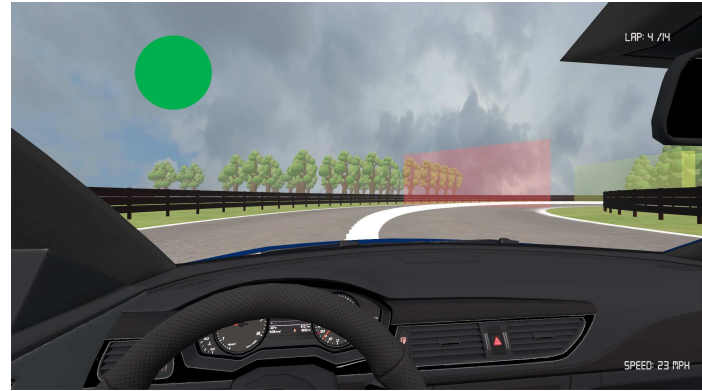

(b) Driving Simulator Interface. Green circle indicates current instruction is accelerate, and red wall indicates a braking response is required on contact. White line represents suggested trajectory for participant to follow.

Fig. (2) Driving Simulation

Subjects were required to progress through the course with the objective of learning to follow the communicated instructions, resulting in efficient traversal of the course, by braking, accelerating, and coasting, at certain locations. Each subject experienced the same location of instructions regardless of ability or performance.

\section{Hypotheses}

H1: The HR group would elicit a P300 of larger amplitude than the LR group, because more working memory resources would be allocated to the task, generating greater neural activity at the moment of instructional stimuli.

H2: The HR group would exhibit a P300 with an increased peak latency, as this may reflect stimulus evaluation or categorisation time [59], where information processing operations are engaged for an increased duration to evaluate instructional stimuli.

\section{Participants}

The participants consisted of 32 healthy adults selected via department wide user study invitations. There were $2 \mathrm{left}$ handers, and 30 right handers. Ages of participants ranged from 19 to 63 overall, and the average of the HR group (M $=23.07 \mathrm{yrs}, \mathrm{SD}=3.53 \mathrm{yrs})$, was slightly younger than the LR group $(\mathrm{M}=27.69 \mathrm{yrs}, \mathrm{SD}=11.04 \mathrm{yrs})$.

\section{E. Independent Variables}

The independent variable in this experiment was the improvement scores of the participants, calculated by dividing the percentage of correct responses in the post-training performance phase by the score in the pre-training performance phase. This result can then be defined as the percentage improvement achieved in the final assessment phase relative to the individuals initial score, reflecting behavioural improvements from the baseline. The scores are recorded using the same technique for both phases. There is less potential to improve if a candidate recorded a high baseline score. This is intentional as there is less for these individuals to learn from the system, and they are likely to record reduced P300 characteristics. To study the main effect of retention, the independent variable was isolated and dichotomised by combining four groups obtained from a standard median split such that: the top eight improving haptic-visual participants combined with the top eight visual participants constituted the HR group, and the bottom eight haptic-visual participants combined with the bottom eight visual participants formed the LR group. For an extended analysis, the groups are decomposed to study the different P300 characteristics produced by modulating the improvement score specifically, creating $0-10 \%, 10-25 \%$, and 25-35\% performance improvement groups. The thresholds of these performance bins are chosen as a theoretical reflection of performance improvement categories specific to this task, where $0-10 \%$ improvement is a low improvement, $10-25 \%$ is a medium improvement, and anything above $25 \%$ is a high improvement. Limitations of categorising variables include reducing information of the dataset and statistical power of the analysis; however, it is a frequently adopted approach in research as it allows for simplified interpretation and presentation of the results.

The percentage of correct responses describes the quantity of instructions correctly followed compared to the total instructions given. This was obtained by observing the instruction communicated by the system and the action performed by the participant. For example, if a participant accelerates in a braking zone then an error would be counted. Each frame spent performing the instructed action is counted as correct, then the total correct responses divided by the total overall responses is the score given for the percentage of instructions followed. This metric observes memory retention of the correct responses, characterised by the correct action in the appropriate zone.

\section{F. Dependent Variables}

1) P300 Response: The dependent variable in this experiment is the P300 component of the ERP, where all eight electrode sites are evaluated, as well as a further analysis of $\mathrm{F}_{\mathrm{z}}$, $\mathrm{C}_{\mathrm{z}}$, and $\mathrm{P}_{\mathrm{z}}$ sites which are typically the focus in neuroscience literature. Characteristics of the P300 component are valuable for interpreting participant information processing: the amplitude measures the amount of neural activity in response to the instructional stimuli, which describes the engagement of information processing operations, where the peak latency is thought to signify the duration of this process [60]. This 


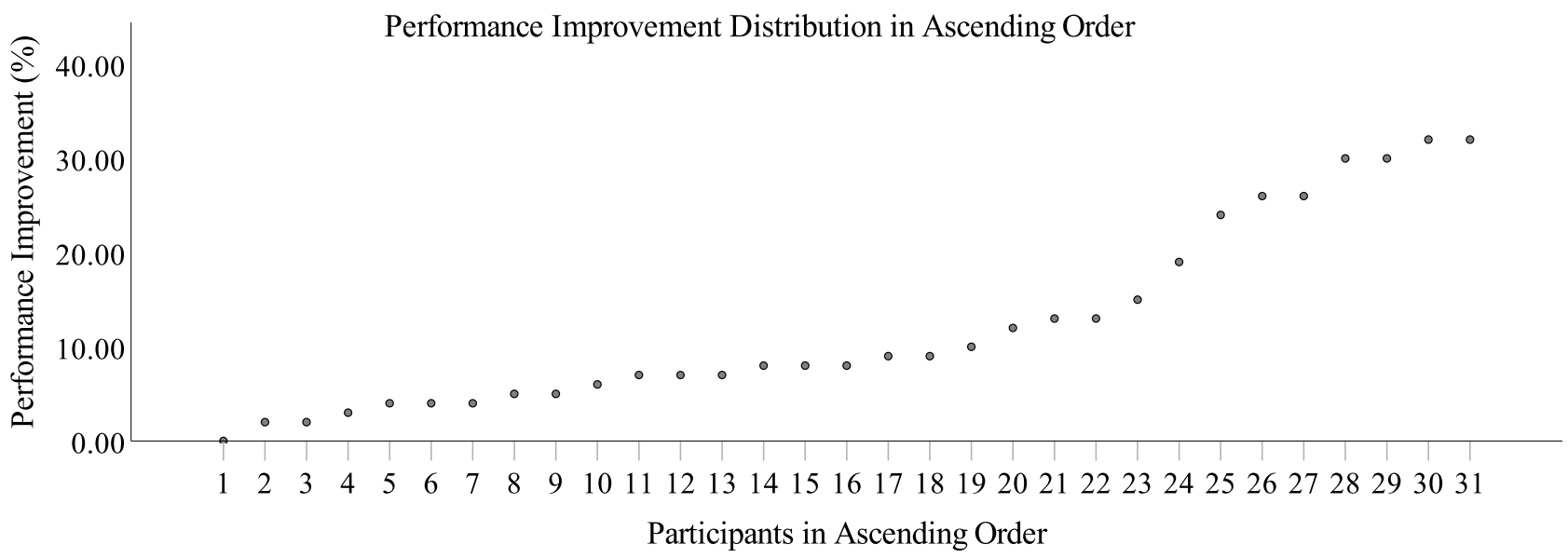

Fig. (3) Distribution of Improvement Scores

amplitude is measured in potential $(\mu \mathrm{V})$, the latency in time (ms), and the total waveform area of the P300 response is measured in the product of potential and time $(\mu \mathrm{Vs})$.

2) P300 Location: ERPs are generally observed in the frontal and parietal lobe in the brain. The parietal lobe is generally responsible for processing sensory information as well as interpreting visual information, whereas the frontal lobe controls important cognitive skills such as emotional expression, problem solving, memory, and judgement. The locations of ERP activation will help reveal the dynamic of information processing in response to the stimuli [61].

\section{G. Task}

There were two types of different lap present in the study: a lap with instructions that the participants were required to follow, termed a training lap, and a lap without instructions where the participants were required to replicate what was learned in the training laps, termed a performance assessment (PA) lap. The training lap is defined by visual representations of the optimal locations to brake, accelerate, and coast, as well as a suggested trajectory for subjects to follow as best possible. The PA lap has no guidance available and is characterised as examining the participants retention from the training phase. In summary, the major difference between these two laps is that there are no visual or haptic instructions present in the PA lap.

Initially the subjects drove two PA laps, which would allow for an evaluation of baseline performance that further laps could be compared against. Subsequently, candidates would complete four training laps, then two PA laps, then four training laps, and a final two PA laps. Each training lap contained 21 pedal-based instructions, for a total of 168 per person, and a total of 2,688 ERP recordings per group. The EEG epochs were extracted from these laps only, as the visual cues were required to elicit the ERP response.

\section{H. Protocol}

Participants were emailed a participant information sheet prior to signing up, containing information about the experiment and requirements of the individual. Upon arrival subjects

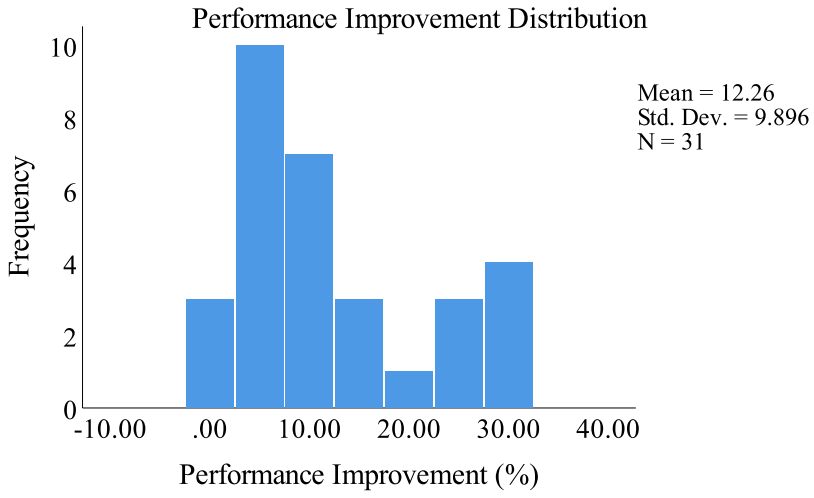

Fig. (4) Frequency Distribution of Improvement Scores

were required to fill out consent forms approving use of their data for the experiment, as well as acknowledging the procedure. A written explanation of the visual guidance was presented to inform candidates of appropriate responses to the system; requirements were challenged verbally, prior to commencement, to ensure understanding.

The EEG headset was fitted to the participant. The right mastoid was cleaned with disinfecting solution and gel electrodes were subsequently attached for grounding, impedance values were then measured and confirmed to be below $40 \mathrm{~K} \Omega$. The participant was seated in the driving seat of the simulator, which was adjusted to fit their profile. Haptic motors were attached to the wrists and ankles of the visual-haptic participants. The EEG data was visually inspected to ensure that reasonable measurements were being recorded. In-ear headphones were provided that would enable system audio and a curtain was then positioned around the simulator to eliminate distractions.

Following the conclusion of the driving element of the study, a simple questionnaire was completed by the participants. This included questions regarding age; attention given to the instructional cues; and general subjective questions, inviting feedback and suggestions, particularly for improving the quality of the simulator.

The study received ethical approval from the Engineering 


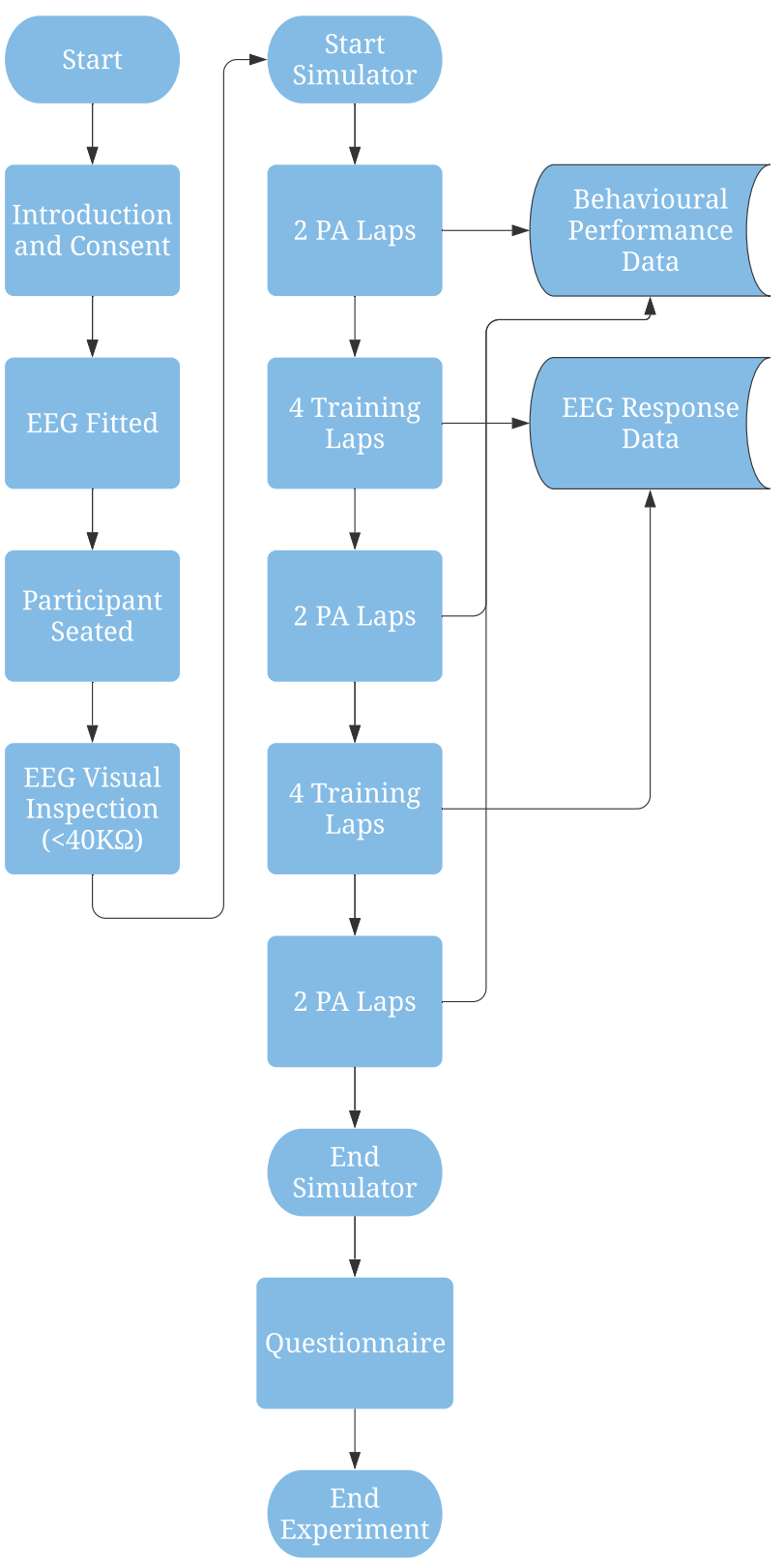

Fig. (5) Simplified Experiment Diagram. Only the final 2 PA laps behavioural performance is compared to the baseline.

and Physical Sciences (EPS) Faculty Research Ethics Committee at Queen's University Belfast, in accordance with the proportionate review process. Consent to use data from the experiment was received from all participants.

\section{Statistical Tests}

Statistical tests were required to examine the difference in the means or medians between the two groups, where the dataset must be recognized as either meeting the assumptions required for a parametric statistical model prior to testing. If the data met the assumptions for a parametric test the independent samples t-test would be chosen to compare the means, otherwise the non-parametric equivalent, the MannWhitney U test, would be selected to accommodate the dataset.
When comparing the groups, a one-way ANOVA would be applied if the data met the assumptions of a parametric test, otherwise the Kruskal-Wallis $\mathrm{H}$ test would be selected. The hypotheses were determined prior to the experiment, hence multiple correction testing was not as critical as in highthroughput experiments without preplanned hypotheses [62]. However, to satisfy this experiment feature and reinforce the validity of the results, the Benjamini and Hochberg false discovery rate was applied to adjust the $p$-Values for the number of tests. This procedure is chosen as it is a powerful and popular tool for decreasing the probability of a Type I error [63]; all $p$-Values were adjusted using this technique.

\section{EEG ANALysis Method}

After the user studies had been concluded the EEG data was loaded into ERPLAB for post-processing. The data was filtered with a Hamming window sinc finite impulse response (FIR) non-causal filter, using a $0.5 \mathrm{~Hz}$ high-pass filter to remove DC offset, and a $30 \mathrm{~Hz}$ low-pass filter to eliminate $50 \mathrm{~Hz}$ line noise. The EEG files were then epoched at all moments where the instructions were interacted with from $100 \mathrm{~ms}$ pre-stimulus to $800 \mathrm{~ms}$ post-stimulus, which was then baseline corrected to the pre-stimulus period.

Once the data was epoched, artefact rejection techniques were utilised to identify low quality EEG data for removal. The moving window peak to peak threshold was applied with a $100 \mu \mathrm{V}$ threshold, a $200 \mathrm{~ms}$ full-width moving window with a $50 \mathrm{~ms}$ step size. The remaining epochs that had a high enough data quality to pass through the filter were averaged across each group to produce one grand average waveform for the HR group, and one for the LR group. A waveform for each site was produced and a variety of procedures were then applied to quantify characteristics of each waveform, including peak to peak amplitude, peak latency, and positive waveform analysis, to determine any statistically significant differences between the two groups by comparing median values. The ERP's were quantified for each individual site and the median was found across all sites. This analysis was executed programmatically in ERPLAB, with the application of various mathematical procedures.

The N200 peak was calculated by pre-defining the window (150-250ms) and observing the largest voltage deflection within that time-period, with the same technique applied to the P300 peak for its relevant window (200-600ms), where the difference between the two yields the peak to peak amplitude (discussed further in Section VI.). The procedure applied to calculate the peak latency was to identify the local peak voltage deflection within the defined window (200-600ms), by selecting the greatest magnitude in the array of values and observing the corresponding latency. The positive area waveform was determined by setting all negative values to zero and calculating the resulting waveform area within the specified window (200-600ms).

\section{RESUlTS}

The waveforms presented in Fig 6. illustrate the average response observed following the instructional cue at the electrode sites $\mathrm{F}_{\mathrm{z}}, \mathrm{C}_{\mathrm{z}}$, and $\mathrm{P}_{\mathrm{z}}$, demonstrating the high retention 
TABLE I

P300 CHARACTERISTICS TABLE

\begin{tabular}{lccccc}
\hline Variable & U Stat & $p$-Value & LR & HR & Difference (\%) \\
\hline Peak to Peak Amplitude & 9.00 & $\mathbf{0 . 0 4 5}$ & $1.838 \mu \mathrm{V}$ & $2.638 \mu \mathrm{V}$ & +43.52 \\
Peak Latency & 0.00 & $<\mathbf{0 . 0 0 1}$ & $286 \mathrm{~ms}$ & $361 \mathrm{~ms}$ & +26.22 \\
Positive Waveform Area & 13.00 & $\mathbf{0 . 0 5 0}$ & $0.2200 \mu \mathrm{Vs}$ & $0.3789 \mu \mathrm{Vs}$ & +72.23 \\
Improvement Score & 0.00 & $<\mathbf{0 . 0 0 1}$ & $4.78 \%$ & $19.98 \%$ & +417.99 \\
Attention to Instructions & 115.50 & 0.861 & $81.9 \%$ & $82.7 \%$ & +0.10 \\
\hline
\end{tabular}

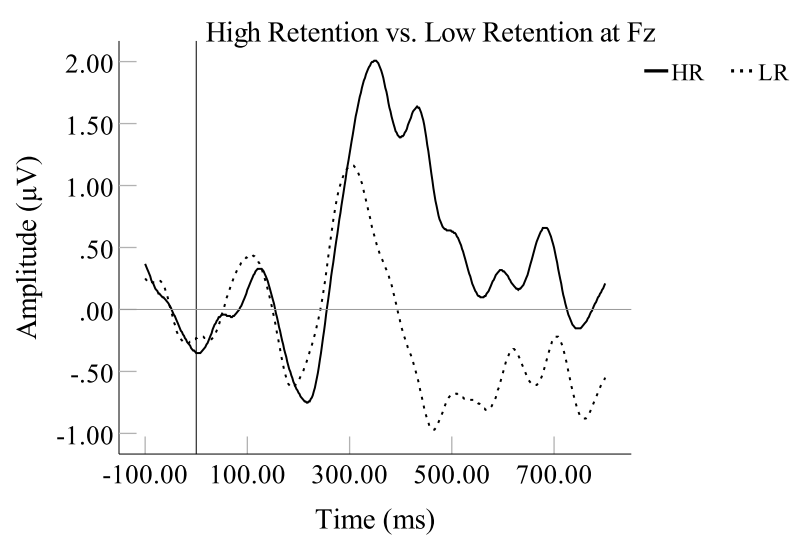

(a) $\mathrm{Fz}$

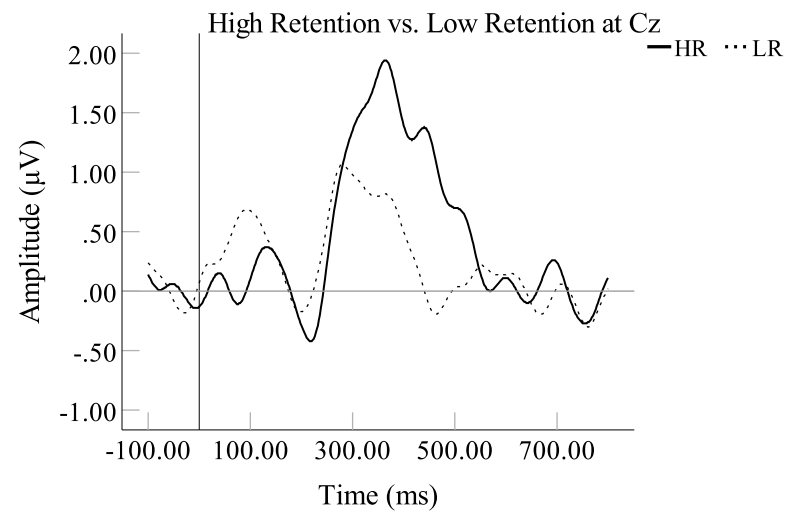

(b) $\mathrm{Cz}$

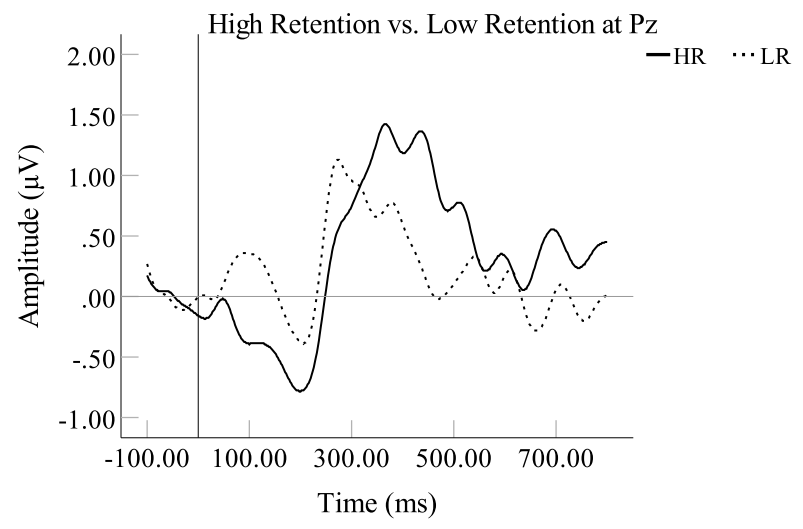

(c) $\mathrm{Pz}$

Fig. (6) High Retention Group vs. Low Retention Group at electrode sites $\mathrm{F}_{\mathrm{z}}, \mathrm{C}_{\mathrm{z}}$, and $\mathrm{P}_{\mathrm{z}}$, with $15 \mathrm{~Hz}$ low-pass filter for cosmetic enhancement. group with a larger P300 amplitude and higher peak latency. Both HR and LR groups contained an equal distribution of haptic and visual-haptic participants. Here, improvement is mathematically defined as the overall difference in the percentage of correct actions produced in the initial assessment compared to the final assessment. Groups for performance improvement, modality, and attention rating had a non-normal distribution and small sample size that made a parametric test unsuitable, thus the statistical test selected was the MannWhitney U test. The HR group performance improvement (M $=+19.98 \%, \mathrm{SD}=8.87 \%)$ was greater than observed in the LR group $(\mathrm{M}=+4.78 \%, \mathrm{SD}=0.0329 \%)(\mathrm{U}=0.00, p<$ $.001)$. There were no statistically significant differences found in retention between the visual-haptic and visual groups ( $\mathrm{U}=$ $114.00, p=.616$ ), hence the results are not further explored in this paper as the objective is to explore learning and memory. Furthermore, no interaction effect was found between modality and the P300 response which was explored by generating two new groups based on modality and measuring the ERP created for each group. When comparing the groups, no statistically significant differences were observed in the metrics where peak to peak amplitude, peak latency, and positive area waveform all tested above the significance threshold $(p>.05)$.

Following the study, participants rated their attention to the instructions on a scale of 1-10, with 10 referring to the highest amount of attention. Subjects that scored less than 4 were omitted from the analysis, which resulted in one participant excluded from the HR group. This was because any performance increase accomplished was unlikely to be a consequence of training, compromising the link to the ERPs and reducing validity of the results. All other participants rated their attention to the instructions as 6 or higher, with both the HR group $(\mathrm{M}=8.27, \mathrm{SD}=0.98)$ and the $\mathrm{LR}$ group $(\mathrm{M}=8.19$, $\mathrm{SD}=1.22)$ subjectively rating attention to the instructions similarly with no significant differences found $(\mathrm{U}=115.50, p$ $=.861$ ), with high averages suggesting adequate engagement with the training. It is hence unlikely that detected effects are a result of modulations in attention, as the groups subjective scores are so similar, further isolating observations of memory.

ERPLAB was used to determine all of the waveform analysis conducted. The peak-to-peak amplitude was measured using the N200-P300 method to measure the change in potential induced by the stimuli, utilised in multiple studies as a measure of the P300 [64]-[66]. This value describes the largest amplitude observed between $200 \mathrm{~ms}$ and $600 \mathrm{~ms}$ minus the smallest value from between 150 and $250 \mathrm{~ms}$, where these values are chosen as they are typical windows for the 
maximum P300 amplitude [67], [68] and the maximum N200 amplitude [69], [70] yielding P300 peak to peak amplitude.

The statistics present the median value and the Median Absolute Deviation (MAD), which are more resistant to the data than the mean equivalent [71]. All significance values given in Section VI. are the exact significance two-tailed values.

Following a comparison of HR and LR P300 characteristics, the groups are broken down further into subgroups of improvement scores. This generates three new groups: $0-10 \%, 10-25 \%$, and $25-35 \%$ improvement over baseline. This further analysis yields better insight into the different P300 characteristics observed in each group.

\section{A. Peak to Peak Amplitude}

The Mann-Whitney $U$ test was performed to compare the medians across the eight sites of the two groups which found that the peak to peak amplitude of the HR group $(\mathrm{M}=$ $2.6380 \mu \mathrm{V}, \mathrm{MAD}=0.3717 \mu \mathrm{V})$ was statistically significant $(\mathrm{U}$ $=9.00, p=.045)$, and greater than the LR group $(\mathrm{M}=$ $1.8381 \mu \mathrm{V}, \mathrm{MAD}=0.2853 \mu \mathrm{V})$. This means that the null hypothesis can be rejected in favour of the alternative hypothesis that the first group's data distribution differs from the second and hence, given the similar data distribution, the two groups produce a different median peak to peak amplitude of the P300 wave across the electrode sites. The HR group peak to peak amplitude was $43.52 \%$ larger than that of the LR. Most ERP studies [51], [72], [73], focus on the sites $F_{z}, C_{z}$, and $P_{z}$, as these locations exhibit the strongest effects in most scenarios; at these sites the HR group peak to peak $(\mathrm{M}=2.7148 \mu \mathrm{V}$, $\mathrm{MAD}=0.1937 \mu \mathrm{V})$ was $38.05 \%$ larger than the LR group (M $=1.9665 \mu \mathrm{V}, \mathrm{MAD}=0.2307 \mu \mathrm{V})$.

The groups were further deconstructed and the KruskalWallis $\mathrm{H}$ test was applied to detect any significant difference between the three groups $(H(2)=16.340, p<.001)$. Post-hoc testing with the Mann-Whitney $\mathrm{U}$ test demonstrates statistical significance between the $25-35 \%$ group and the $0-10 \%$ group ( $\mathrm{U}=0.00, p<.001)$, as well as between the $10-25 \%$ group and the $0-10 \%$ group $(\mathrm{U}=0.00, p<.001)$, but no significant differences between the $25-35 \%$ group and the $10-25 \%$ group $(\mathrm{U}=18.00, p=.181)$ for peak to peak amplitude. Both the $25-35 \%$ and $10-25 \%$ group produce significantly greater peak to peak amplitude than the $0-10 \%$ group but produce a similar amplitude to the other (see Table III).

\section{B. Peak Latency}

The peak latencies of the waveforms describe the time of the peak amplitude between 200ms and 600ms after the stimuli. A Mann-Whitney U test was applied to compare the medians of the two groups finding that the difference between the HR group $(\mathrm{M}=361.00 \mathrm{~ms}, \mathrm{MAD}=2.50 \mathrm{~ms})$ and the $\mathrm{LR}$ group $(\mathrm{M}=286.00 \mathrm{~ms}, \mathrm{MAD}=19.00 \mathrm{~ms})$ was statistically significant $(\mathrm{U}=0.00, p<.001)$. These values are low because every waveform from the HR group had a higher value for latency than the LR group. The peak latency was found to be $26.22 \%$ higher on average for HR than LR, and at the sites $F_{z}, C_{z}$, and $\mathrm{P}_{\mathrm{z}}$, the $\mathrm{HR}$ group $(\mathrm{M}=362.00 \mathrm{~ms}$, $\mathrm{MAD}=2.22 \mathrm{~ms})$ had a $33.09 \%$ higher peak latency than the LR group $(\mathrm{M}=$ $272.00 \mathrm{~ms}, \mathrm{MAD}=17.78 \mathrm{~ms}$ ).

The groups were further decomposed and the KruskalWallis $\mathrm{H}$ test was applied to detect any statistically significant differences between the three groups $(H(2)=15.478, p<$ .001). Post-hoc testing with the Mann-Whitney U test demonstrates statistical significance between the $25-35 \%$ group and the $0-10 \%$ group ( $\mathrm{U}=0.00, p<.001)$, as well as between the $10-25 \%$ group and the $0-10 \%$ group $(\mathrm{U}=0.00, p<.001)$, but no significant differences between the $25-35 \%$ group and the $10-25 \%$ group $(\mathrm{U}=21.50, p=.181)$ for peak latency. Both the $25-35 \%$ and $10-25 \%$ group produce significantly greater peak latency than the $0-10 \%$ group but produce similar peak latencies to the other (see Table III).

\section{Positive Waveform Area}

A positive waveform analysis was conducted in ERPLAB to determine the value of the positive waveform area between $200 \mathrm{~ms}$ and $600 \mathrm{~ms}$. This dataset was also required the MannWhitney $U$ test which found that the difference between the HR group $(\mathrm{M}=0.3789 \mu \mathrm{Vs}, \mathrm{MAD}=0.0648 \mu \mathrm{Vs})$ and the LR group $(\mathrm{M}=0.2200 \mu \mathrm{Vs}, \mathrm{MAD}=0.0644 \mu \mathrm{Vs})$ was statistically significant $(\mathrm{U}=13.00, p=.05)$. On average, the HR group had a P300 wave that was $72.23 \%$ greater than that of the $\mathrm{LR}$, and at the sites $\mathrm{F}_{\mathrm{z}}, \mathrm{C}_{\mathrm{z}}$, and $\mathrm{P}_{\mathrm{z}}$, the $\mathrm{HR}$ group $(\mathrm{M}=$ $0.3738 \mu \mathrm{Vs}, \mathrm{MAD}=0.0246 \mu \mathrm{Vs}$ ) produced a positive area that was $96.74 \%$ larger than the LR group $(\mathrm{M}=0.1900 \mu \mathrm{Vs}$, MAD $=0.0333 \mu \mathrm{Vs}$ ).

The groups were further deconstructed and the KruskalWallis $\mathrm{H}$ test was applied to detect any significant difference between the three groups $(H(2)=13.732, p=.001)$. Posthoc testing with the Mann-Whitney $U$ test finds statistical significance between the $25-35 \%$ group and the $0-10 \%$ group $(\mathrm{U}=0.00, p<.001)$, as well as between the $10-25 \%$ group and the $0-10 \%$ group $(\mathrm{U}=9.50, p=.023)$, and no significant differences between the $25-35 \%$ group and the $10-25 \%$ group $(\mathrm{U}=14.00, p=.084)$ for positive waveform area. Both the 25 $35 \%$ and $10-25 \%$ group produce significantly greater positive waveform area than the $0-10 \%$ group (see Table III).

\section{Scalp Maps}

Scalp maps in Fig 7. depict the mean voltage deflection exhibited between $200 \mathrm{~ms}$ and $600 \mathrm{~ms}$. This allows a visualisation of the areas in the brain that were the most active in response to the training instructions. It can be observed that the HR participants demonstrate greater neural activity in the frontal and parietal cortices, that have been consistently linked with working memory in the literature [57].

\section{DISCUSSION}

The results demonstrate a greater peak to peak amplitude for $\mathrm{HR}$, which describes greater neural activity in response to the stimuli, or more specifically, greater summations of postsynaptic potentials from populations of synchronously active, primarily cortical neurons [45] [46]. The HR group were more successful at reproducing the instructions experienced in 
TABLE II

P300 COMPARISON STATISTICS GROUPED BY IMPROVEMENT SCORE

\begin{tabular}{|c|c|c|c|c|c|c|}
\hline \multirow{2}{*}{ Variable } & \multicolumn{3}{|c|}{ 25-35\% Improv. } & \multicolumn{3}{|c|}{ 10-25\% Improv. } \\
\hline & U Stat & $p$-Value & $\%$ Diff. $^{1}$ & U Stat & $p$-Value & $\%$ Diff. $^{1}$ \\
\hline \multicolumn{7}{|l|}{ 10-25\% Improv. } \\
\hline Peak to Peak Amplitude & 18.00 & 0.181 & $+9.56 \%$ & - & - & - \\
\hline Peak Latency & 21.50 & 0.279 & $-1.92 \%$ & - & - & - \\
\hline Positive Waveform Area & 14.00 & 0.084 & $+36.67 \%$ & - & - & - \\
\hline \multicolumn{7}{|l|}{ 0-10\% Improv. } \\
\hline Peak to Peak Amplitude & 0.00 & $<\mathbf{0 . 0 0 1}$ & $+68.21 \%$ & 9.50 & 0.023 & $+53.53 \%$ \\
\hline Peak Latency & 0.00 & $<0.001$ & $+14.42 \%$ & 0.00 & $<\mathbf{0 . 0 0 1}$ & $+16.67 \%$ \\
\hline Positive Waveform Area & 0.00 & $<0.001$ & $+100.00 \%$ & 0.00 & $<\mathbf{0 . 0 0 1}$ & $+46.34 \%$ \\
\hline
\end{tabular}

TABLE III

P300 CHARACTERISTICS BY IMPROVEMENT SCORE

\begin{tabular}{lccc}
\hline Variable & $0-10 \%$ Improv. & $10-25 \%$ Improv. & $25-35 \%$ Improv. \\
\hline Peak to Peak Amplitude (MAD) & $1.840 \mu \mathrm{V}(0.307 \mu \mathrm{V})$ & $2.825 \mu \mathrm{V}(0.315 \mu \mathrm{V})$ & $3.095 \mu \mathrm{V}(0.319 \mu \mathrm{V})$ \\
Peak Latency (MAD) & $312 \mathrm{~ms}(11.63 \mathrm{~ms})$ & $364 \mathrm{~ms}(32.13 \mathrm{~ms})$ & $357 \mathrm{~ms}(5.00 \mathrm{~ms})$ \\
Positive Waveform Area (MAD) & $0.205 \mu \mathrm{Vs}(0.029 \mu \mathrm{Vs})$ & $0.300 \mu \mathrm{Vs}(0.075 \mu \mathrm{Vs})$ & $0.410 \mu \mathrm{Vs}(0.064 \mu \mathrm{Vs})$ \\
\hline
\end{tabular}

training, hence the results suggest a relationship between the neural activity as a response to the instruction stimuli and the amount of instruction information retained, anticipated in the first hypothesis. This echoes previous studies that have linked the P300 to memory and learning processes such as encoding, retention, and recollection of the stimulus [57], contributing the instance of an applied training environment. In particular, the results appear to link with working memory, and the overall attentional resources allocated at the moment of instruction.

Further breakdown of the results indicates that there are significant differences between different improvement scores for peak to peak amplitude. Both the 25-35\% group and the $10-25 \%$ group produce statistically significant differences compared with the $0-10 \%$ group, but no significant differences between them, hence the magnitude of neural activity at instruction is similar in both groups. There is some evidence that the $25-35 \%$ group have produced slightly larger amplitudes as the median value is marginally greater, indicating that there could be a small effect size. This suggests there could be a limitation on the efficacy of using the peak to peak amplitude as a measurement and that this particular response dynamic is similar. This could be for a variety of reasons, such as an upper limit on the amplitude of the P300 response causing smaller deviations at greater magnitudes. A larger experiment with increased data would be required to determine the differences with improved resolution.

The latency at which the component peaks has been described as an indicator of stimulus evaluation or categorisation time, with longer latencies indicating more effortful categorisation [60], [74]. The peak latency observed is higher for the HR group, which signifies that the information was processed

\footnotetext{
${ }^{1}$ Difference is calculated for the column, relative to the row. For example, the $25-35 \%$ group had a median peak to peak amplitude that was $9.56 \%$ greater than the $10-25 \%$ group, as seen in Table II.
}

for longer as the measurement indicates that the neurons fired for a greater duration. This suggests that candidates who improved more had put more effort into categorising stimuli, predicted in the second hypothesis. Further breakdown of the results suggests that there is not a major difference between the $25-35 \%$ and $10-25 \%$ group for peak latency, signifying that categorisation times were similar in both cases. It is possible that there is an upper limit on the amount of categorisation time necessary, or even an optimal associated with this particular task.

Positive waveform analysis describes the positive area under the curve, describing the overall magnitude of the information processing response. This technique is often considered the optimal for analysing the P300 waveform as it is not as susceptible to noise as other techniques, and the selection of measurement window is much less influential on the result [75]. This measurement is larger for the HR group at nearly double the magnitude for the $F_{z}, C_{z}$, and $P_{z}$ regions, implying that the overall information processing response to the instructions was greater. Further breakdown of the results finds statistical significance between certain groups. There is no statistical significance between the $25-35 \%$ group and the $10-25 \%$ group, but there could be a small effect size which would require more results to analyse further. This technique observes greater differences between the groups than the other techniques, which is possibly because peak to peak amplitude and peak latency only measure cognitive processes preceding the peak, whereas positive waveform analysis captures operations over the entirety of the defined window. Furthermore, this suggests that there is still some difference in complex information processing operations between the groups, which is also reflected in the concomitant behavioural improvement.

All three of the presented characteristics that describe the P300 are important for gaining an overall description of 


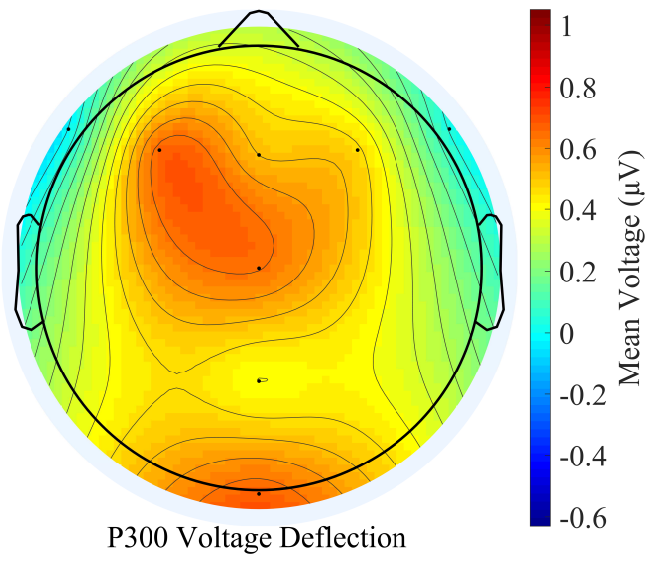

(a) High Retention

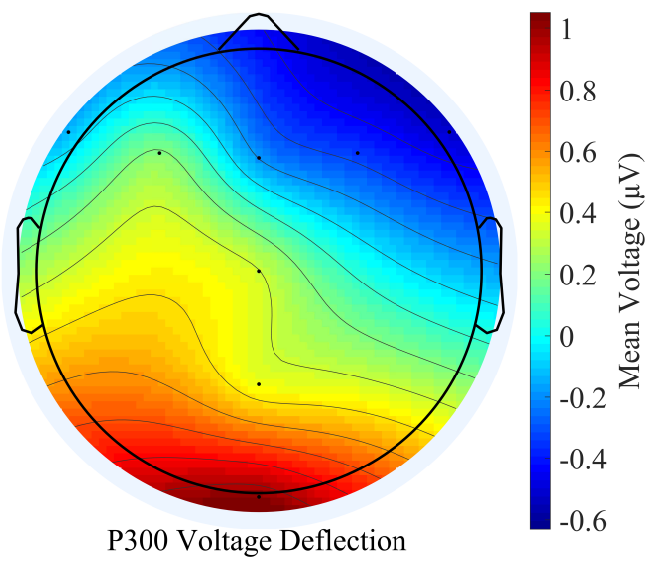

(b) Low Retention

Fig. (7) Scalp Map of Average P300 Voltage Deflection Between $200 \mathrm{~ms}$ and $600 \mathrm{~ms}$. The scalp map presented is a visualisation and accurate only around the electrodes displayed. Areas where there are no electrodes present are subject to interpolation and are not claimed to be accurate.

the information processing that occurred as a response to instructional stimuli.

The scalp maps offer a visualisation of the neural activity location which illustrates the elements of the brain most involved in the cognitive processes. The parietal lobe is generally responsible for processing sensory information as well as interpreting visual information, whereas the frontal lobe controls important cognitive skills such as emotional expression, problem solving, memory, and judgement. There is significantly greater activation in both the frontal and parietal lobes for the HR participants which suggests that these elements of the brain are being utilised more effectively. It is mainly the frontal lobe that is responsible for working memory, so it is expected to observe this area as more active for higher retentions, supporting the theory that the neural activity observed is a result of complex memory processes occurring in the brain. Greater frontal activation has been previously documented in skill acquisition [61], which is further demonstrated in this experiment. In this regard, the experiment offers further evidence of hyperfrontality in skill

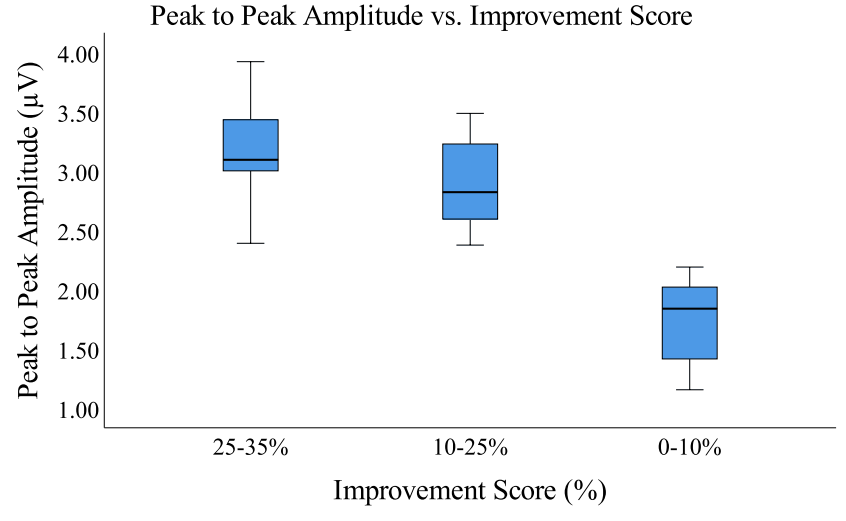

(a) Peak to Peak Amplitude

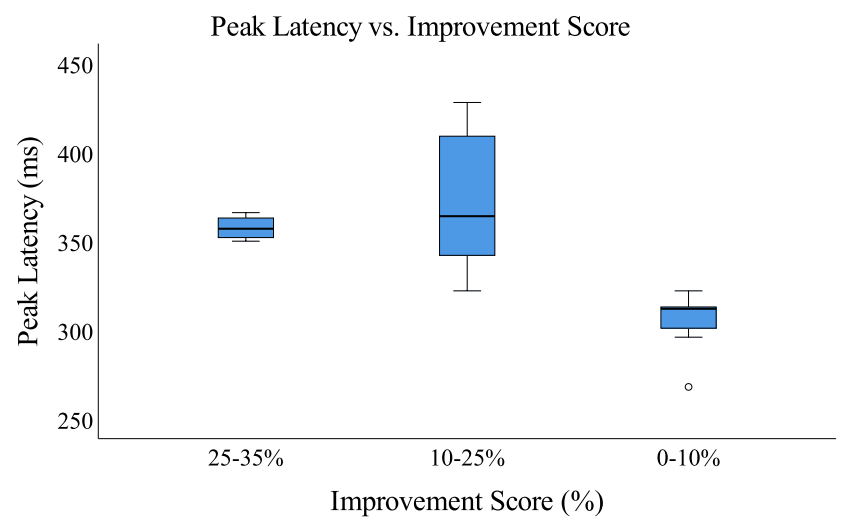

(b) Peak Latency

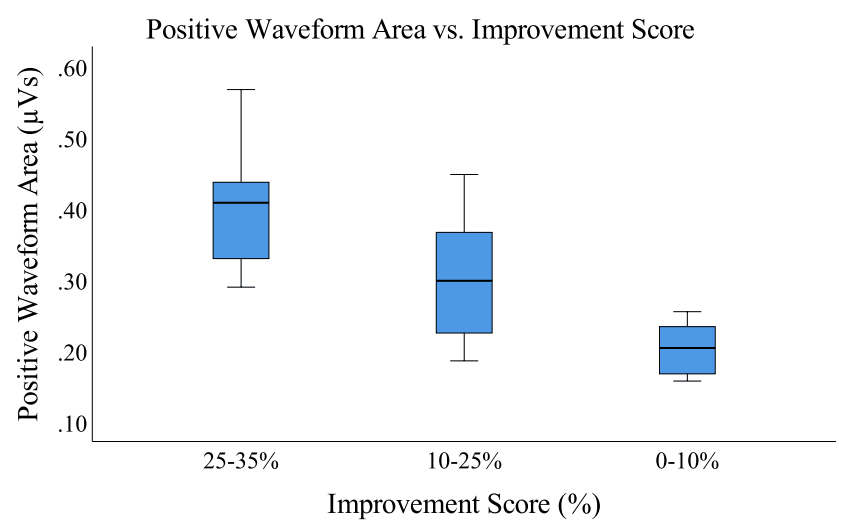

(c) Positive Waveform Area

Fig. (8) Box Plots of Waveform Characteristics Across Electrode Sites

acquisition.

The P300 has been demonstrated to modulate with attentional resource allocation in the wider literature [50], [55], [76], it hence seems likely that the amount of attention assigned to the instructions will vary the P300 characteristics. Furthermore, individuals with high working memory capacities may make more efficient use of neural resources to keep their attention focused on the task-relevant information, thus the working memory abilities of an individual will likely modulate the P300 [57], [77]. It is possible that both the natural working memory abilities of an individual and the amount of 
attention given to the instructions are modulating the P300 response in this context. It is important to reiterate that this experiment offers evidence of between-subject variability, not within-subject variability, however, there is reasonable evidence of this from the wider literature which is valuable for interpretation.

If high-resolution perception of the P300 was available, the literature links to working memory suggest it would assist in detecting learning in virtual training systems, via detection of individual working memory capacity and applied attention. It could then be employed in a human-computer training system such that the training can be adapted and optimised to accommodate different training preferences. It could also be applied to interpret the quality of training cues, as participants will learn more from effective instructions, hence designers could run studies to compare training quality among different systems.

\section{LIMITATIONS AND FUTURE WORK}

This study is limited to comparing the grand average ERP waveforms of the groups because of the implementation demanded by the experiment design. While differences between the groups have been successfully analysed, it is important to conduct further research for superior understanding of the relationship between extremes. With the technology currently available, wet EEG could be utilised to obtain higher quality responses as it is less susceptible to noise [78], potentially allowing for a higher resolution analysis. This could also be achieved with a similar study containing more participants. Another option is to increase the amount of total ERP responses by redesigning the experiment to have more laps. This was not possible in this experiment because participant attention would likely deteriorate beyond this time frame; it would also compromise subjects desire to participate due to an increased overall duration.

Furthermore, a major limitation of this technique is the requirement of external stimuli to elicit the P300 response on many occasions to produce a reliable result. However, there is a whole field dedicated to improving the signal quality of the EEG [79], [80], as well as improving single trial capture and analysis of the P300 response [81], [82]; with advancements in this field it could be possible to discern ERPs with far fewer trials. With improvements in the technology a higher quality ERP could be obtained for each participant, then a linear regression model could be used to further understand the relationship between the P300 and the quantity learned, which would help greatly in developing the P300 as a measurement tool for virtual training environments. This would then allow predictions of post-training performance to be made, based on the characteristics of an individuals P300 observed in training.

\section{CONCLUSION}

A virtual performance driver training system was developed using the Unity Game Engine that was designed to give visual instructions about the location and timing of an action that participants were required to perform, in order to teach a fixed sequence of actions that would result in efficient traversal of the supplied driving course. Both the action required and the action performed by the subject were recorded, which would act as a metric for determining the amount of instructions correctly followed.

Two groups were then created by taking the amount of instructions correctly followed during the last performance assessment phase and comparing that to the amount of instructions followed prior to any training and separating them to generate groups of high and low retention participants. This technique facilitated comparison between the ERPs generated in the brain at the point of instruction for the HR and LR groups. The groups were then further decomposed to facilitate a more insightful analysis.

The Enobio-8 Dry EEG Headset was used to record the brainwaves during the procedure, and signals were sent from the simulator to the NIC software using LSL streams to record the moment that a new instruction was administered. Data was processed and ERPs were extracted, which were grand averaged based on the magnitude of improvement from pre-training to post-training. Across the eight electrode sites statistical significance was found between the HR groups and the LR groups for the peak to peak amplitude $(\mathrm{U}=9.00, p=$ $.045)$, the peak latency $(\mathrm{U}=0.00, p<.001)$, and the positive area $(U=13.00, p=.05)$ which were all greater for the HR group.

In conclusion, the latency and amplitude of the signal are modulated by retention which suggests that the characteristics of this signal, that describe the magnitude and duration of neural activity associated with the stimuli, are potentially suitable for detecting working memory in virtual environments with stimuli-based learning procedures. There is evidence that positive waveform area is the better technique for discriminating between behavioural improvement as the results suggest a closer relationship, which could be because it captures more of the neurological process. However, the P300 is a complex cognitive response and additional research is required to better understand its relationship with memory in this context. Significant technological advancements are mandatory for high-resolution implementations, but this experiment has successfully demonstrated the potential of a practical realisation.

This paper has contributed evidence regarding the relationship between the P300 and retention in virtual training environments, and as EEG technology improves and virtual training systems become more intelligent, the use of the P300 to recognise learning in functional virtual training systems should be researched further.

\section{ACKNOWLEDGMENT}

The authors would like to thank Gerry Rafferty and Jim Norney for their assistance on the project. As well as a big thanks to Jack Easson of the Queen's University Belfast Racing Team for helping with tuning the vehicle physics and designating optimal zones for specific driving actions. Also, thank you to Zachary W. Petzel and Zara Gibson for their guidance on the EEG. 


\section{REFERENCES}

[1] K. Lee, "Augmented reality in education and training," TechTrends, vol. 56, no. 2, pp. 13-21, 2012.

[2] S. Webel, U. Bockholt, T. Engelke, N. Gavish, M. Olbrich, and C. Preusche, "An augmented reality training platform for assembly and maintenance skills," Robotics and autonomous systems, vol. 61, no. 4, pp. 398-403, 2013.

[3] C. Basdogan, S. De, J. Kim, M. Muniyandi, H. Kim, and M. A. Srinivasan, "Haptics in minimally invasive surgical simulation and training," IEEE computer graphics and applications, vol. 24, no. 2, pp. 56-64, 2004.

[4] L. Cheng and M. Tavakoli, "A multilateral impedance-controlled system for haptics-enabled surgical training and cooperation in beating-heart surgery," International Journal of Intelligent Robotics and Applications, vol. 3, no. 3, pp. 314-325, 2019.

[5] N. Gavish, T. Gutiérrez, S. Webel, J. Rodríguez, M. Peveri, U. Bockholt, and F. Tecchia, "Evaluating virtual reality and augmented reality training for industrial maintenance and assembly tasks," Interactive Learning Environments, vol. 23, no. 6, pp. 778-798, 2015.

[6] K. Abhari, J. S. Baxter, E. C. Chen, A. R. Khan, T. M. Peters, S. de Ribaupierre, and R. Eagleson, "Training for planning tumour resection: augmented reality and human factors," IEEE Transactions on Biomedical Engineering, vol. 62, no. 6, pp. 1466-1477, 2014.

[7] R. M. Viglialoro, N. Esposito, S. Condino, F. Cutolo, S. Guadagni, M. Gesi, M. Ferrari, and V. Ferrari, "Augmented reality to improve surgical simulation: lessons learned towards the design of a hybrid laparoscopic simulator for cholecystectomy," IEEE Transactions on Biomedical Engineering, vol. 66, no. 7, pp. 2091-2104, 2018.

[8] Z. Liang, K. Zhou, and K. Gao, "Development of virtual reality serious game for underground rock-related hazards safety training," IEEE Access, vol. 7, pp. 118639-118 649, 2019.

[9] G. Westerfield, A. Mitrovic, and M. Billinghurst, "Intelligent augmented reality training for motherboard assembly," International Journal of Artificial Intelligence in Education, vol. 25, no. 1, pp. 157-172, 2015.

[10] D. Riofrio-Luzcando, J. Ramirez, and M. Berrocal-Lobo, "Predicting student actions in a procedural training environment," IEEE Transactions on Learning Technologies, vol. 10, no. 4, pp. 463-474, 2017.

[11] K. VanLehn, J. Wetzel, S. Grover, and B. Van De Sande, "Learning how to construct models of dynamic systems: an initial evaluation of the dragoon intelligent tutoring system," IEEE Transactions on Learning Technologies, vol. 10, no. 2, pp. 154-167, 2016.

[12] J. J. Roldán, E. Crespo, A. Martín-Barrio, E. Peña-Tapia, and A. Barrientos, "A training system for industry 4.0 operators in complex assemblies based on virtual reality and process mining," Robotics and ComputerIntegrated Manufacturing, vol. 59, pp. 305-316, 2019.

[13] F. Ferrati, J. A. Erkoyuncu, and S. Court, "Developing an augmented reality based training demonstrator for manufacturing cherry pickers," Procedia CIRP, vol. 81, pp. 803-808, 2019.

[14] C.-K. Yang, Y.-H. Chen, T.-J. Chuang, K. Shankhwar, and S. Smith, "An augmented reality-based training system with a natural user interface for manual milling operations," Virtual Reality, pp. 1-13, 2019.

[15] M. W. Schmidt, K.-F. Kowalewski, M. L. Schmidt, E. Wennberg, C. R. Garrow, S. Paik, L. Benner, M. P. Schijven, B. P. Müller-Stich, and F. Nickel, "The heidelberg vr score: development and validation of a composite score for laparoscopic virtual reality training," Surgical endoscopy, vol. 33, no. 7, pp. 2093-2103, 2019.

[16] J. A. Blanco, M. K. Johnson, K. J. Jaquess, H. Oh, L.-C. Lo, R. J. Gentili, and B. D. Hatfield, "Quantifying cognitive workload in simulated flight using passive, dry eeg measurements," IEEE Transactions on Cognitive and Developmental Systems, vol. 10, no. 2, pp. 373-383, 2016.

[17] G. Cartocci, A. G. Maglione, G. Vecchiato, G. Di Flumeri, A. Colosimo, A. Scorpecci, P. Marsella, S. Giannantonio, P. Malerba, G. Borghini et al., "Mental workload estimations in unilateral deafened children," in 2015 37th Annual International Conference of the IEEE Engineering in Medicine and Biology Society (EMBC). IEEE, 2015, pp. 1654-1657.

[18] R. M. Mehmood, R. Du, and H. J. Lee, "Optimal feature selection and deep learning ensembles method for emotion recognition from human brain eeg sensors," Ieee Access, vol. 5, pp. 14 797-14 806, 2017.

[19] K. Takahashi and A. Tsukaguchi, "Remarks on emotion recognition from multi-modal bio-potential signals," in SMC'03 Conference Proceedings. 2003 IEEE International Conference on Systems, Man and Cybernetics. Conference Theme-System Security and Assurance (Cat. No. 03CH37483), vol. 2. IEEE, 2003, pp. 1654-1659.

[20] Y. Cui, Y. Xu, and D. Wu, "Eeg-based driver drowsiness estimation using feature weighted episodic training," IEEE transactions on neural systems and rehabilitation engineering, vol. 27, no. 11, pp. 2263-2273, 2019.

[21] P. Arico, G. Borghini, G. Di Flumeri, N. Sciaraffa, A. Colosimo, and F. Babiloni, "Passive bci in operational environments: insights, recent advances, and future trends," IEEE Transactions on Biomedical Engineering, vol. 64, no. 7, pp. 1431-1436, 2017.

[22] B. Blankertz, L. Acqualagna, S. Dähne, S. Haufe, M. Schultze-Kraft, I. Sturm, M. Ušćumlic, M. A. Wenzel, G. Curio, and K.-R. Müller, "The berlin brain-computer interface: progress beyond communication and control," Frontiers in Neuroscience, vol. 10, p. 530, 2016.

[23] E. Harmon-Jones and J. S. Beer, Methods in social neuroscience. Guilford Press, 2012.

[24] Y. Inoue, K. Nanba, K. Kojima, H. Mitani, Arai, and Heii, "P300 abnormalities in patients with severe sleep apnea syndrome," Psychiatry and clinical neurosciences, vol. 55, no. 3, pp. 247-248, 2001.

[25] D. H. Blackwood, D. M. St Clair, W. J. Muir, and J. C. Duffy, "Auditory p300 and eye tracking dysfunction in schizophrenic pedigrees," Archives of General Psychiatry, vol. 48, no. 10, pp. 899-909, 1991.

[26] B. Reuter and D. Linke, "P300 and coma," in Topographic brain mapping of EEG and evoked potentials. Springer, 1989, pp. 192-196.

[27] L. J. Prinzel III, F. G. Freeman, M. W. Scerbo, P. J. Mikulka, and A. T. Pope, "Effects of a psychophysiological system for adaptive automation on performance, workload, and the event-related potential p300 component," Human factors, vol. 45, no. 4, pp. 601-614, 2003.

[28] O. Dressler, G. Schneider, G. Stockmanns, and E. Kochs, "Awareness and the eeg power spectrum: analysis of frequencies," British journal of anaesthesia, vol. 93, no. 6, pp. 806-809, 2004.

[29] Z. Zhang and K. K. Parhi, "Low-complexity seizure prediction from ieeg/seeg using spectral power and ratios of spectral power," IEEE transactions on biomedical circuits and systems, vol. 10, no. 3, pp. 693706, 2015.

[30] D. Lai, M. B. B. Heyat, F. I. Khan, and Y. Zhang, "Prognosis of sleep bruxism using power spectral density approach applied on eeg signal of both emg1-emg2 and ecg1-ecg2 channels," IEEE Access, vol. 7, pp. 82 553-82 562, 2019.

[31] L. R. Krol, L. M. Andreessen, and T. O. Zander, "Passive braincomputer interfaces: a perspective on increased interactivity," in BrainComputer Interfaces Handbook. CRC Press, 2018, pp. 69-86.

[32] Y. Cui and D. Wu, "Eeg-based driver drowsiness estimation using convolutional neural networks," in International Conference on Neural Information Processing. Springer, 2017, pp. 822-832.

[33] C.-H. Chuang, Z. Cao, Y.-K. Wang, P.-T. Chen, C.-S. Huang, N. R. Pal, and C.-T. Lin, "Dynamically weighted ensemble-based prediction system for adaptively modeling driver reaction time," arXiv preprint arXiv:1809.06675, 2018.

[34] S.-H. Oh, Y.-R. Lee, and H.-N. Kim, "A novel eeg feature extraction method using hjorth parameter," International Journal of Electronics and Electrical Engineering, vol. 2, no. 2, pp. 106-110, 2014.

[35] R. Jenke, A. Peer, and M. Buss, "Feature extraction and selection for emotion recognition from eeg," IEEE Transactions on Affective Computing, vol. 5, no. 3, pp. 327-339, 2014.

[36] B. Hjorth, "Eeg analysis based on time domain properties," Electroencephalography and clinical neurophysiology, vol. 29, no. 3, pp. 306-310, 1970.

[37] M. B. Kurt, N. Sezgin, M. Akin, G. Kirbas, and M. Bayram, "The annbased computing of drowsy level," Expert Systems with Applications, vol. 36, no. 2, pp. 2534-2542, 2009.

[38] A. Chowdhury, R. Shankaran, M. Kavakli, and M. M. Haque, "Sensor applications and physiological features in drivers drowsiness detection: A review," IEEE Sensors Journal, vol. 18, no. 8, pp. 3055-3067, 2018.

[39] W. Klimesch, "Memory processes, brain oscillations and eeg synchronization," International journal of psychophysiology, vol. 24, no. 1-2, pp. 61-100, 1996.

[40] W. Klimesch, M. Doppelmayr, H. Schimke, and B. Ripper, "Theta synchronization and alpha desynchronization in a memory task," Psychophysiology, vol. 34, no. 2, pp. 169-176, 1997.

[41] G. Matthews, L. Reinerman-Jones, J. Abich IV, and A. Kustubayeva, "Metrics for individual differences in eeg response to cognitive workload: Optimizing performance prediction," Personality and Individual Differences, vol. 118, pp. 22-28, 2017.

[42] C. Dussault, J.-C. Jouanin, and C.-Y. Guezennec, "Eeg and ecg changes during selected flight sequences," Aviation, space, and environmental medicine, vol. 75, no. 10, pp. 889-897, 2004.

[43] C. Dussault, J.-C. Jouanin, M. Philippe, and C.-Y. Guezennec, "Eeg and ecg changes during simulator operation reflect mental workload and vigilance," Aviation, space, and environmental medicine, vol. 76, no. 4, pp. 344-351, 2005. 
[44] B. Wortelen, A. Unni, J. W. Rieger, and A. Lüdtke, "Towards the integration and evaluation of online workload measures in a cognitive architecture," in 2016 7th IEEE International Conference on Cognitive Infocommunications (CogInfoCom). IEEE, 2016, pp. 000 011-000 016.

[45] T. Allison, C. C. Wood, C. McCarthy, M. Coles, E. Donchin, and S. Porges, Psychophysiology: Systems, processes, and applications. New York: The Guildford Press, 1986.

[46] M. G. Coles and M. D. Rugg, Event-related brain potentials: An introduction. Oxford University Press, 1995

[47] J. Polich, "Updating p300: an integrative theory of p3a and p3b," Clinical neurophysiology, vol. 118, no. 10, pp. 2128-2148, 2007.

[48] F. Aloise, P. Aricò, F. Schettini, A. Riccio, S. Salinari, D. Mattia, F. Babiloni, and F. Cincotti, "A covert attention p300-based braincomputer interface: Geospell," Ergonomics, vol. 55, no. 5, pp. 538-551, 2012.

[49] M. Fabiani, G. Gratton, D. Karis, E. Donchin et al., "Definition, identification, and reliability of measurement of the p300 component of the event-related brain potential," Advances in psychophysiology, vol. 2, no. S 1, p. 78, 1987.

[50] J. Polich, "Neuropsychology of $\mathrm{p} 300$, , Oxford handbook of event-related potential components, vol. 159, p. 88, 2012.

[51] Y.-W. Jeon and J. Polich, "Meta-analysis of p300 and schizophrenia: Patients, paradigms, and practical implications," Psychophysiology, vol. 40, no. 5 , pp. $684-701,2003$

[52] J. Polich and J. Corey-Bloom, "Alzheimer's disease and p300: review and evaluation of task and modality," Current Alzheimer Research, vol. 2, no. 5, pp. 515-525, 2005

[53] S. Yamaguchi and R. T. Knight, "Age effects on the p300 to novel somatosensory stimuli," Electroencephalography and clinical neurophysiology, vol. 78, no. 4, pp. 297-301, 1991.

[54] J. Polich, C. Ladish, and F. E. Bloom, "P300 assessment of early alzheimer's disease," Electroencephalography and Clinical Neurophysiology/Evoked Potentials Section, vol. 77, no. 3, pp. 179-189, 1990.

[55] I. Käthner, S. C. Wriessnegger, G. R. Müller-Putz, A. Kübler, and S. Halder, "Effects of mental workload and fatigue on the p300, alpha and theta band power during operation of an erp (p300) brain-computer interface," Biological psychology, vol. 102, pp. 118-129, 2014.

[56] Z. Gibson, J. Butterfield, M. Rodger, B. Murphy, and A. Marzano, "Use of dry electrode electroencephalography (eeg) to monitor pilot workload and distraction based on p300 responses to an auditory oddball task," in International Conference on Applied Human Factors and Ergonomics. Springer, 2018, pp. 14-26.

[57] H. U. Amin, A. S. Malik, N. Kamel, W.-T. Chooi, and M. Hussain, "P300 correlates with learning \& memory abilities and fluid intelligence," Journal of neuroengineering and rehabilitation, vol. 12, no. 1 , p. $87,2015$.

[58] A. Delorme and S. Makeig, "Eeglab: an open source toolbox for analysis of single-trial eeg dynamics including independent component analysis," Journal of neuroscience methods, vol. 134, no. 1, pp. 9-21, 2004.

[59] E. Donchin, "Event-related brain potentials: A tool in the study of human information processing," in Evoked brain potentials and behavior. Springer, 1979, pp. 13-88.

[60] M. Kutas, G. McCarthy, and E. Donchin, "Augmenting mental chronometry: the p300 as a measure of stimulus evaluation time," Science, vol. 197, no. 4305, pp. 792-795, 1977.

[61] A. J. Wintink, S. J. Segalowitz, and L. J. Cudmore, "Task complexity and habituation effects on frontal p300 topography," Brain and Cognition, vol. 46, no. 1-2, pp. 307-311, 2001.

[62] R. A. Armstrong, "When to use the b onferroni correction," Ophthalmic and Physiological Optics, vol. 34, no. 5, pp. 502-508, 2014.

[63] G. H. Green and P. J. Diggle, "On the operational characteristics of the benjamini and hochberg false discovery rate procedure," Statistical applications in genetics and molecular biology, vol. 6, no. 1, 2007.

[64] S. Krishnamurti, "P300 auditory event-related potentials in binaural and competing noise conditions in adults with central auditory processing disorders," Contemporary Issues in Communication Science and Disorders, vol. 28, no. Spring, pp. 40-47, 2001.

[65] D. De Venuto, V. F. Annese, and G. Mezzina, "Remote neuro-cognitive impairment sensing based on p300 spatio-temporal monitoring," IEEE Sensors Journal, vol. 16, no. 23, pp. 8348-8356, 2016.

[66] D. D. Venuto, V. F. Annese, G. Mezzina, F. Scioscia, M. Ruta, E. D. Sciascio, and A. S. Vincentelli, "A mobile health system for neurocognitive impairment evaluation based on $\mathrm{p} 300$ detection," ACM Transactions on Cyber-Physical Systems, vol. 2, no. 4, pp. 1-21, 2018.

[67] D. A. Bolton and W. R. Staines, "Age-related loss in attention-based modulation of tactile stimuli at early stages of somatosensory processing," Neuropsychologia, vol. 50, no. 7, pp. 1502-1513, 2012.
[68] Y. Wu and X. Zhou, "The p300 and reward valence, magnitude, and expectancy in outcome evaluation," Brain research, vol. 1286, pp. 114$122,2009$.

[69] J. Wang, H. Miyazato, M. Randall, H. Hokama, K.-I. Hiramatsu, and C. Ogura, "The n200 abnormalities of auditory event-related potentials in patients with panic disorder," Progress in Neuro-Psychopharmacology and Biological Psychiatry, vol. 27, no. 6, pp. 1013-1021, 2003.

[70] T. Rosburg, P. Trautner, T. Dietl, T. Kral, C. E. Elger, and M. Kurthen, "The influence of repetition and famousness on the intracranially recorded temporobasal n200.” Behavioral neuroscience, vol. 119, no. 4, p. 876, 2005.

[71] C. Leys, C. Ley, O. Klein, P. Bernard, and L. Licata, "Detecting outliers: Do not use standard deviation around the mean, use absolute deviation around the median," Journal of Experimental Social Psychology, vol. 49, no. 4, pp. 764-766, 2013

[72] M. L. Jongsma, N. J. Gerrits, C. M. van Rijn, R. Q. Quiroga, and J. H. Maes, "Event related potentials to digit learning: Tracking neurophysiologic changes accompanying recall performance," International journal of psychophysiology, vol. 85, no. 1, pp. 41-48, 2012.

[73] H. U. Amin, A. S. Malik, N. Badruddin, N. Kamel, and M. Hussain, "Effects of stereoscopic 3d display technology on event-related potentials (erps)," in 2015 7th International IEEE/EMBS Conference on Neural Engineering (NER). IEEE, 2015, pp. 1084-1087.

[74] A. Magliero, T. R. Bashore, M. G. Coles, and E. Donchin, "On the dependence of p300 latency on stimulus evaluation processes," Psychophysiology, vol. 21, no. 2, pp. 171-186, 1984.

[75] S. J. Luck, An introduction to the event-related potential technique. MIT press, 2014

[76] C. D. Wickens, J. Isreal, and E. Donchin, "The event related cortical potential as an index of task workload," in Proceedings of the Human Factors Society Annual Meeting, vol. 21, no. 4. SAGE Publications Sage CA: Los Angeles, CA, 1977, pp. 282-286.

[77] S. Dong, L. M. Reder, Y. Yao, Y. Liu, and F. Chen, "Individual differences in working memory capacity are reflected in different erp and eeg patterns to task difficulty," Brain research, vol. 1616, pp. 146$156,2015$.

[78] K. E. Mathewson, T. J. Harrison, and S. A. Kizuk, "High and dry? comparing active dry eeg electrodes to active and passive wet electrodes," Psychophysiology, vol. 54, no. 1, pp. 74-82, 2017.

[79] V. Nathan and R. Jafari, "Design principles and dynamic front end reconfiguration for low noise eeg acquisition with finger based dry electrodes," IEEE transactions on biomedical circuits and systems, vol. 9, no. 5, pp. 631-640, 2015.

[80] P. Gajbhiye, R. K. Tripathy, A. Bhattacharyya, and R. B. Pachori, "Novel approaches for the removal of motion artifact from eeg recordings," IEEE Sensors Journal, vol. 19, no. 22, pp. 10600-10608, 2019.

[81] J. Li, Z. L. Yu, Z. Gu, W. Wu, Y. Li, and L. Jin, "A hybrid network for erp detection and analysis based on restricted boltzmann machine," IEEE Transactions on Neural Systems and Rehabilitation Engineering, vol. 26, no. 3, pp. 563-572, 2018.

[82] S. K. Haider, A. Jiang, M. A. Jamshed, H. Pervaiz, and S. Mumtaz, "Performance enhancement in p300 erp single trial by machine learning adaptive denoising mechanism," IEEE Networking Letters, vol. 1, no. 1 , pp. 26-29, 2018. 